\title{
Cultura Corporal como Linguagem: Uma Experiência de Formação de Professores
}

\author{
Mônica Caldas Ehrenberg*, Marcos Garcia Neira* \\ Faculdade de Educação da Universidade de São Paulo
}

*Autores para correspondência: monica.ce@usp.br; mgneira@usp.br

\begin{abstract}
RESUMO
O presente trabalho objetiva compartilhar uma experiência pedagógica realizada no âmbito do curso de licenciatura em Pedagogia da USP, na disciplina EDM 0677 - Cultura Corporal: Fundamentação, Metodologia e Vivências, ministrada anualmente desde 2007. A disciplina, responsável pelo estudo dos gestos e da expressão corporal, é um lugar de investigação e problematização do patrimônio cultural corporal. Ao longo desses anos, temos percebido grande envolvimento das(os) alunas(os), pois a proposta metodológica, até então inédita para muitas(os) delas(es), instiga um processo ao mesmo tempo inventivo, crítico e reflexivo envolvendo a linguagem corporal. Parece-nos claro que a experiência tem permitido produzir novos sentidos e significados para a cultura corporal na formação de futuros professores e do seu papel no projeto político-pedagógico da instituição escolar. Sobretudo, tem possibilitado a descoberta do prazer através das vivências baseadas em propostas lúdicas.
\end{abstract}

Palavras-Chave: Formação de Professores; Linguagem Corporal; Cultura Corporal.

\begin{abstract}
This paper's purpose is to share an educational experience performed throughout the Education course at USP, in the subject EDM 0677 - Corporal Culture: Reason, Methodology and Experience, ministered annually since 2007. The subject, which is responsible for the study of gestures and body expression, is a place of investigation and problematization of the corporal cultural heritage. Throughout these years, we have noticed great involvement of the students, for the methodological proposal, which was until now unprecedented for many of them, instigates a process that is also inventive, critical and reflexive, involving body language. It seems clear that the experience has permitted us to produce new ways and meanings for the corporal culture in the formation of future teachers and their role in the political-educational project of the educational institution. Above all, it has enabled the finding of pleasure through experiences based on recreational proposals.
\end{abstract}

Keywords: Teacher Training; Body Language; Body Culture.

\section{A Experiência}

A experiência aqui compartilhada surgiu da iniciativa dos dois docentes envolvidos, mediante a realização de um planejamento de ações que contemplam, prioritariamente, o estudo e a experimentação de manifestações culturais corporais, aqui compreendidas como o conjunto de práticas particularmente corporais que visam a entender a expressão corporal como linguagem. Sinteticamente falando, trata-se dos conhecimentos e representações socialmente disseminados acerca das práticas corporais, incluindo diversas maneiras de vivenciá-las, interpretá-las e concebê-las, além dos múltiplos olhares acerca dos padrões éticos e estéticos presentes na sociedade.
Propositalmente utilizamos o termo experiência para contar nosso percurso, reconhecendo e nos apoiando no conceito trazido por Benjamim (1994): diz o crítico ser a experiência algo raro de se conseguir na contemporaneidade. Isso porque experiência não tem relação com informação, e sim com conhecimento.

Bondía (2002) em sua suave escrita corrobora esta ideia, afirmando que vivemos num tempo-espaço social pautado pela informação. $\mathrm{O}$ acesso fácil e rápido à informação tem nos transformado, segundo o autor, numa sociedade da informação. Tudo sabemos, tudo conhecemos. E o pior: opinamos a respeito de tudo! Ainda que de 
maneira rasa e superficial, temos a necessidade de opinar sobre algo de que fomos informados.

A disciplina aqui compartilhada caminha na contramão dessa agilidade e superficialidade. Busca-se, apesar do curto tempo de um semestre de seu oferecimento, mergulhar nas possibilidades de as/os alunas/os se conhecerem como sujeitos por inteiro, de apropriarem-se do entendimento de que todos nós somos fruto de uma construção social e de que não se justifica a dicotomia corpo-mente na compreensão do ser humano.

A universidade, numa busca cada vez mais intensa rumo à especialização (POMBO, 2005) e ao produtivismo acadêmico, colabora para que os docentes trabalhem isoladamente ou em grupos restritos e se afastem dos colegas, sobretudo no trabalho com o ensino da graduação, cada vez menos valorizado, constituindo-se num espaço em que, lamentavelmente, predomina o descompromisso. Porém, foi justamente a partir do envolvimento com a graduação, da valorização do trabalho em parceria, além do reconhecimento dos limites em relação ao saber de cada um sobre determinados temas, que decidimos concretizar esta experiência de troca de conhecimentos e integração de saberes.

A Universidade tem que se preparar, não apenas para não oferecer resistências ao trabalho interdepartamental, mas, para, além disso, promover esse tipo de experiências, facilitar novos tipos de configurações disciplinares, aceitar fazer investigação sobre os novos problemas que se colocam à ciência contemporânea. Criar, se possível, circunstâncias e mecanismos que favoreçam a compreensão dos próprios fenômenos interdisciplinares que estão a ocorrer na ciência e na universidade. (POMBO, 2005, p. 13).

Com essa premissa, as(os) graduandas(os) são desafiadas(os) durante todo o processo educacional a participarem ativamente e de forma criativa da disciplina, vivenciando corporalmente as atividades propostas, além de realizarem leituras, discussões, oficinas com profissionais convidados e estudos do meio envolvendo a temática da cultura corporal. Trata-se de colocar os corpos em ação, produzindo conhecimentos. Os corpos singulares de cada aluna(o) e da(o) professora(r) que participam das atividades propostas vivem o "[...] componente lúdico da cultura corporal, redescobrindo o prazer, a inteireza e a técnica-arte da linguagem corporal" (AYOUB, 2007, p. 76), numa constante interlocução entre a universidade, como instituição formal de ensino, e os conhecimentos da cultura corporal.

As práticas corporais e artísticas fazem parte desse lugar de aprender. Distribuídas nas temáticas de brincadeiras, danças, lutas, esportes e ginásticas, as aulas promovem o entrecruzamento dos repertórios das(os) alunas(os), da(o) professora $(r)$ dos conhecimentos científicos e populares. Adotando os pressupostos epistemológicos e metodológicos da perspectiva cultural da Educação Física (NEIRA, 2018), as duas primeiras aulas são dedicadas à realização do mapeamento do repertório cultural corporal da turma por meio de provocações do tipo: relacione as práticas corporais que fizeram parte da sua infância, que você realiza nos momentos de lazer, que acessou durante alguma viagem etc. Essa lista é digitada, disponibilizada no site da disciplina, e a turma é convidada a categorizar as manifestações arroladas em: brincadeiras, danças, lutas, esportes e ginásticas. Esse material subsidia todas as vivências, pois as(os) estudantes recorrem a ele para selecionar as práticas corporais que serão experimentadas, ressignificadas, aprofundadas e ampliadas durante as aulas (Figura 1).

Por meio da troca de significados, os saberes iniciais são ampliados com destaque para sua dimensão pedagógica que subsidiará as futuras intervenções docentes. $\mathrm{O}$ ambiente lúdico e aberto estimula discentes e docentes a apresentarem suas próprias experiências formais e informais com o tema, contribuindo sobremaneira para o enriquecimento cultural e para a formação profissional. Isso se dá ao organizarmos grupos e, esses, um por vez, apresentam o modo como conhecem a prática corporal e os significados que atribuem a ela. Em 


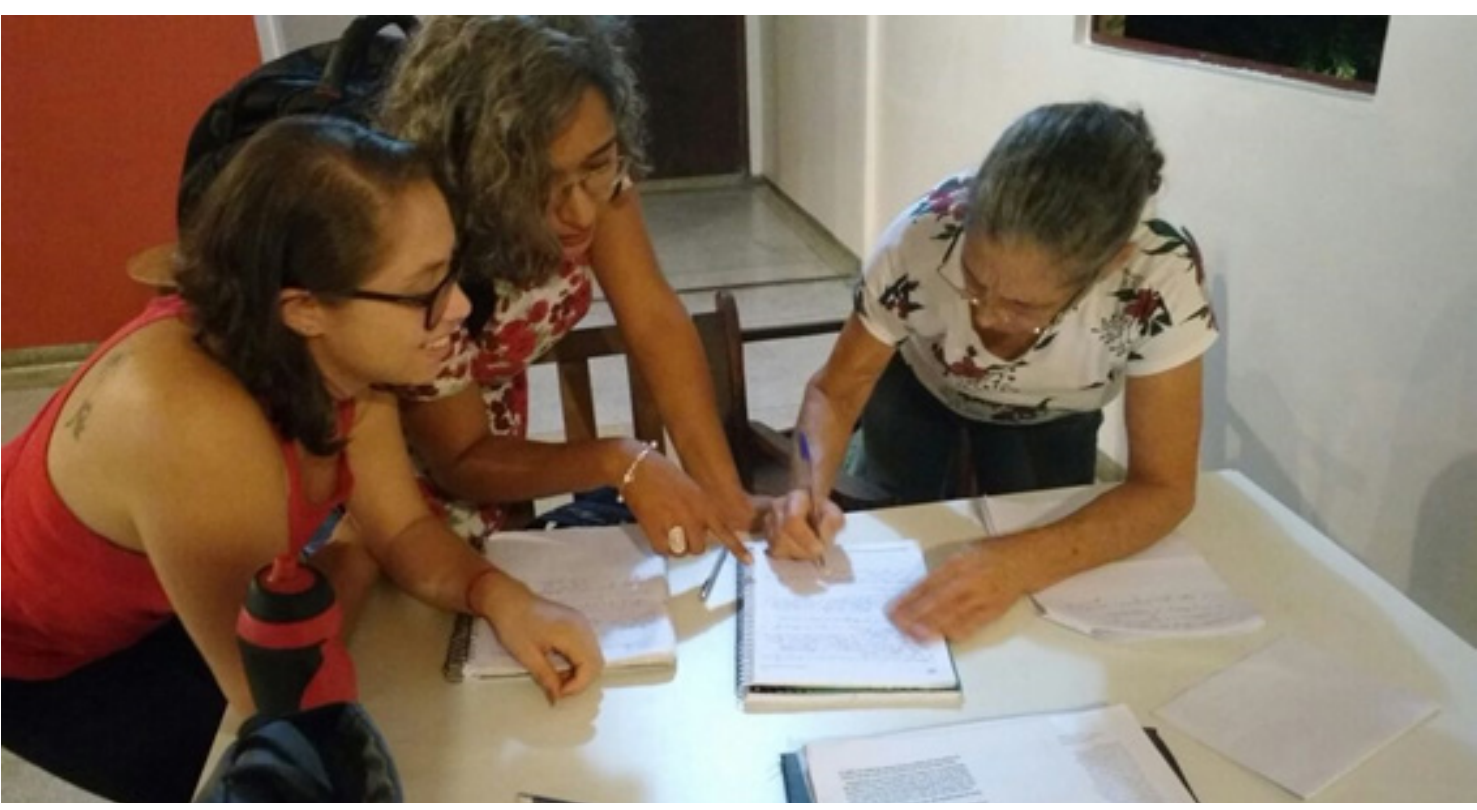

Figura 1 - Alunas mapeando o repertório da cultura corporal.

seguida, a turma realiza vivências dialogadas para que todas(os) possam sugerir modificações, de modo a ajustar ao máximo a manifestação às características da turma e dos recursos disponíveis.

Algumas datas são reservadas para as atividades de aprofundamento e ampliação, ocasiões em que os grupos interagem com outros conhecimentos mediante o acesso a entrevistas ou vivências orientadas por convidados, pesquisas bibliográficas ou na internet, tutoriais etc. Acompanhando todo o processo, destacam-se os procedimentos de registro e avaliação. O primeiro implica a documentação do percurso realizado por fotos, anotações, relatos escritos, filmagens, desenhos etc. O segundo recupera as informações registradas para dimensionar em que medida as atividades realizadas proporcionam o alcance dos objetivos estipulados.

Em termos conceituais, é a perspectiva pós-crítica da educação que inspira o desenvolvimento das atividades de ensino. Sem eleger um ponto de vista como prioritário, os textos, imagens, filmes empregados como recursos didáticos potencializam a interação das(os) estudantes com múltiplas visões sobre o mesmo assunto. As práticas corporais são abordadas da mesma maneira: independentemente das suas histórias "oficiais", outras narrativas e possibilidades são apresentadas e discutidas. O intuito é sensibilizar as(os) participantes para os riscos da fixação de verdades ou definições. O que se espera é que façam o mesmo no desempenho das suas funções docentes, ou seja, que as crianças, jovens e adultos com quem vierem a trabalhar possam travar contato com as várias explicações da realidade.

Um claro exemplo dessa dinâmica é uma aula destinada às práticas corporais circenses. Como manifestação da cultura do corpo, as práticas existentes no circo são claramente reconhecidas pelo grupo, porém muitas vezes com um reconhecimento exclusivamente midiático, pautado por um senso comum que restringe a grandiosidade dessa manifestação a algumas poucas figuras como o palhaço (de nariz vermelho) e a estrutura circense de lona colorida.

Partindo do que já é familiar ao grupo, objetivamos ampliar e aprofundar o reconhecimento acerca da manifestação estudada. Apresentação de vídeos sobre o contexto histórico circense, vivência prática de elementos corporais que constituem o circo, tais como exercícios de solo, atividades de dramatização, além de construção de materiais de malabares que poderão ser posteriormente confeccionados em escolas com materiais de baixo custo, além de discussões de textos sobre o cenário atual da manifestação, corroboram a ressignificação do imaginário inicial que se tem acerca do circo. 
É importante que os estudantes sintam que um dos papéis da educação é permitir a apropriação crítica dos conhecimentos estudados. Reconhecer e partir do que o grupo de alunos já traz é de suma importância, mas transcender esse conhecimento é fundamental (Figura 2).

Outro traço marcante da disciplina é a sua conclusão com a elaboração de um produto final vinculado diretamente aos temas desenvolvidos: pode ser uma coreografia, uma brincadeira, um portfólio eletrônico, uma dramatização, atividade pedagógica etc., desde que compartilhado com a turma que analisará e apresentará suas contribuições.

O grupo todo de alunos participantes da disciplina torna-se coparticipante do processo avaliativo. A apresentação dos trabalhos é feita a todo o grupo, que, posteriormente, expõe seus comentários, pareceres, análises. Nesse momento, vivenciamos uma avaliação participativa em que a discussão sobre o processo da disciplina vem à tona e é confrontada com o produto apresentado pelos grupos. As discussões e análises costumam ser ricas e tornam-se momentos de grande aprendizagem. A avaliação deixa claramente de ser momento de atribuição exclusiva de nota e passa a ser vista como parte integrante do processo de construção do conhecimento.

Com o passar dos anos, a procura de alunas(os) pela disciplina EDM-0677 - Cultura Corporal: Fundamentação, Metodologia e Vivências, que é optativa para todos os cursos de licenciatura da USP, tem crescido e se consolidado não apenas entre os que buscam compreender a Educação Física e suas perspectivas mais contemporâneas, mas também entre alunas(os) que já atuam como professoras(es) ou auxiliares de professoras na educação infantil e primeiras séries da educação fundamental. Esse aumento na procura também tem minimizado alguns desconfortos e desafios que eram mais frequentes no início do oferecimento da mesma.

As primeiras turmas da disciplina foram marcadas por alguns momentos bastante desafiadores tanto para nós docentes, quanto para as alunas(os). A exposição de corpo inteiro era ainda algo muito peculiar e distante das experiências vividas anteriormente na graduação pela maioria das alunas(os). O fato de precisar tirar os sapatos para a realização de algumas vivências ou ainda dar as mãos ou abraçar os colegas de turma era tido como uma dificuldade a ser superada pelas(os) participantes. Isso fazia com que nós, docentes responsáveis pelas disciplinas, precisássemos lançar mão de novas estratégias a cada aula a fim de minimizar tal impacto e propiciar um ambiente de confiança e companheirismo entre o grupo (Figuras 3 e 4).

Com o passar dos anos, a partir do "boca a boca" das(os) próprias(os) alunas(os) que já haviam participado da disciplina, essa resistência

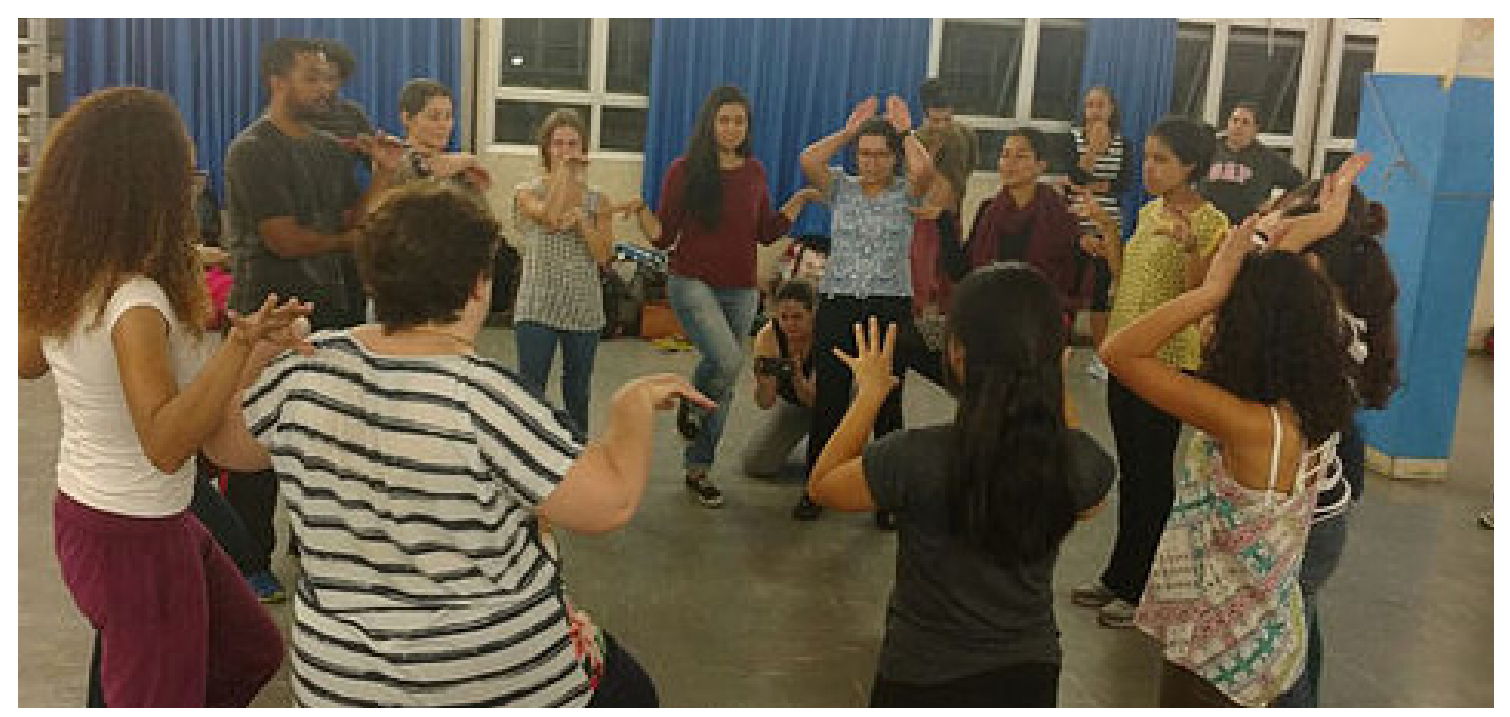

Figura 2 - Vivência da manifestação da cultura corporal: brincadeira. 


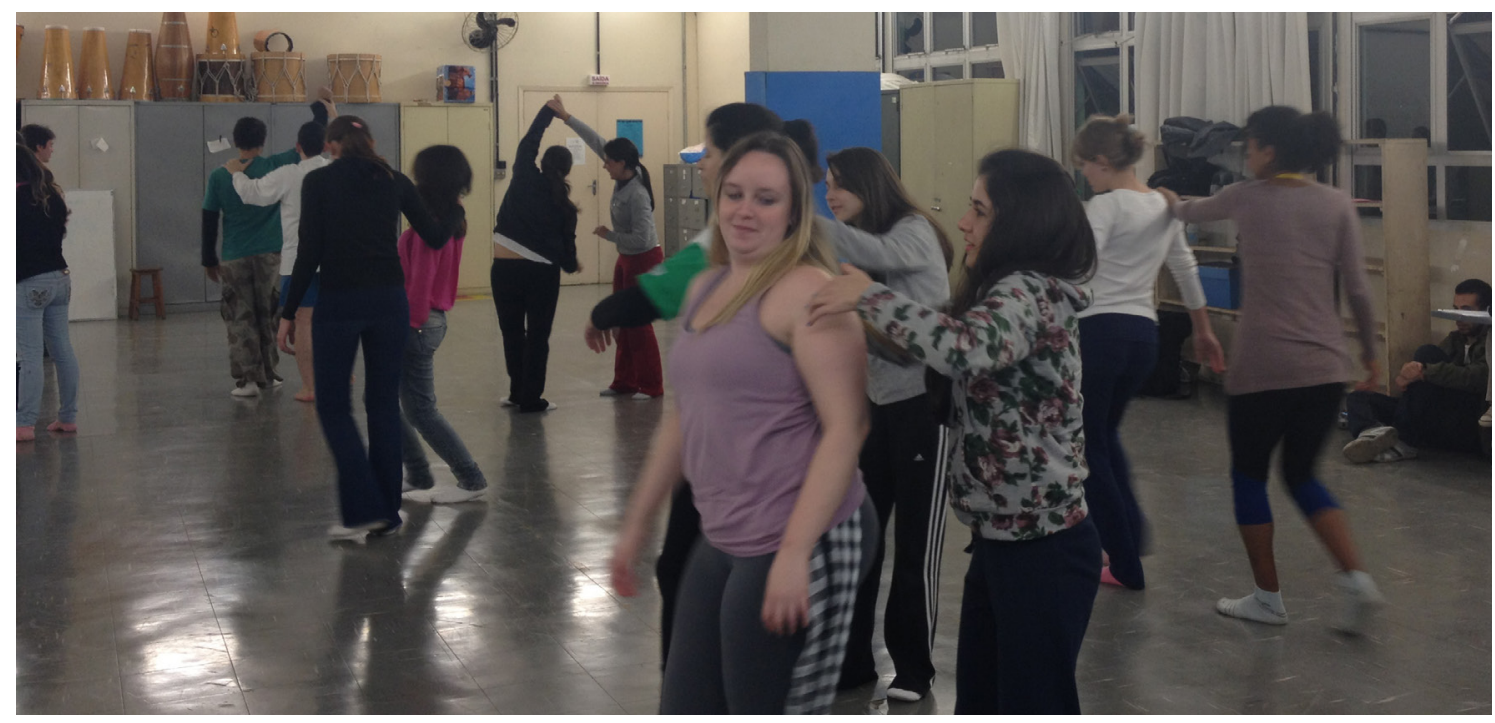

Figura 3 - Vivência da manifestação da cultura corporal: jogo de condução.

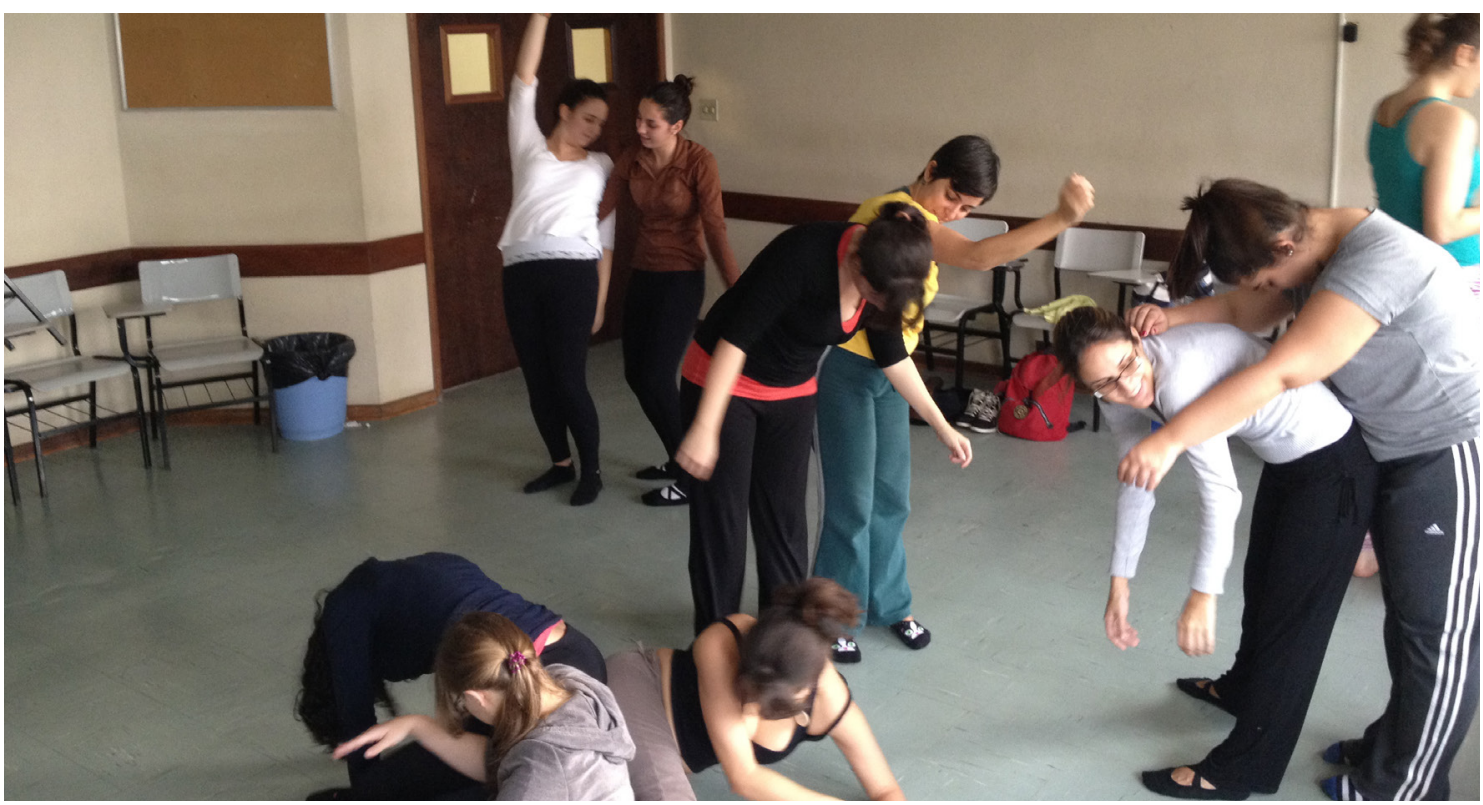

Figura 4 - Vivência da manifestação da cultura corporal: dança.

e dificuldade anterior foram sendo diminuídas. As(os) ingressantes já se matriculavam sabendo que tais práticas seriam experimentadas e assim já começam a chegar mais abertas(os) e dispostas(os) a participar da disciplina com inteireza.

Os relatos ao final do semestre, em forma de roda de conversa ou avaliações escritas, nos deixam evidente que muitas/os alunas/os descobrem, a partir da participação da disciplina, que possuem vivas possibilidades corporais da infância que estavam adormecidas. Destacamos a seguir o relato de uma aluna sobre a questão:
Nunca imaginei que pudesse pular corda. Por ter uma deficiência visual e usar óculos muito grossos desde criança, meus professores sempre me impediram de participar de aulas com corda por alegarem ser muito perigoso. Cresci acreditando que isso não era para mim. Estou muito emocionada por ter conseguido pular. Mais emocionada ainda por saber que é possível e que alguém me permitiu. Nunca vou impedir um aluno meu de tentar. Só não é possível pular corda quando não se tenta, e isso cada um sabe de si. Tenho a certeza de que meus alunos vão tentar e só vão 
parar se assim quiserem. (Aluna M. da turma de 2012$)^{1}$.

Ao longo do semestre, muitos relatos de tentativas e experimentações das práticas vividas na disciplina e nos locais de trabalho também nos aguçam a pesquisar mais profundamente esse universo. É frequente as(os) alunas(os) contarem em aula como se deu uma tentativa ou outra de adaptação das vivências a que foram submetidas(os) junto aos seus alunos da escola. É certo que nesses momentos destacamos não fazer parte dos objetivos da disciplina oferecer vivências e atividades a serem desenvolvidas diretamente com as crianças. Nossa intenção primeira é oportunizar que futuras(os) professoras(es) possam experimentar sensações, vibrações, que as práticas corporais revelam.

No entanto, muitas estudantes consideram possível que o mesmo seja vivenciado por seus alunos ou contam aos colegas da disciplina adaptações que fizeram para possibilitar a vivência das crianças.

Os esforços da disciplina estão despendidos em contribuir para a produção de novos significados acerca da educação física escolar. Busca-se inquietar e permitir reflexão para que os alunos desmistifiquem a Educação Física tida como sinônimo de esporte.

\section{Considerações Finais}

$\mathrm{O}$ prazer e a alegria não são finalidades da escola, mas são sentimentos presentes no caminho da criança, jovem ou adulto que vão (ou deveriam ir) ao encontro de um determinado tipo de saber que, em semelhança com os demais, tem de ser valorizado. Essa parece ser uma das grandes contribuições dessa disciplina na formação de pedagogas(os). Sobretudo, tem possibilitado a descoberta do prazer pela prática corporal por meio de propostas lúdicas. Ao menos é o que se pode abstrair dos comentários das(os) concluintes. Parece-nos claro que a experiência tem permitido produzir novos sentidos e significados acerca da compreensão da cultura corporal na formação de futuras(os) professoras(es) e do seu papel no projeto político-pedagógico da instituição escolar.

\section{Nota}

1 Relato escrito em avaliação de final de curso. $\mathrm{Na}$ ocasião foram solicitadas duas questões: a primeira, que as alunas escrevessem qual o seu entendimento sobre Educação Física na escola, após a passagem pela disciplina; a segunda questão abria espaço para qualquer tipo de exposição, consideração, crítica, sugestão que a aluna quisesse. Foi nessa segunda parte que a aluna M. escreveu a citação destacada.

\section{Referências Bibliográficas}

AYOUB, E. Ginástica Geral e Educação Fúsica Escolar. 2. ed. Campinas: Editora da Unicamp, 2007.

BENJAMIN, Walter. "O Narrador. Considerações sobre a Obra de Nicolai Leskov". In: Magia e Técnica, Arte e Politica: Ensaios sobre Literatura e História da Cultura. 7 ed. São Paulo: Brasiliense, 1994, pp. 197-221.

BONDÍA, Jorge Larrosa. "Notas sobre a Experiência e o Saber de Experiência". Revista Brasileira de Educação, n. 19, 2002, pp. 20-28.

NEIRA, Marcos Garcia. Educação Física Cultural: Inspiração e Prática Pedagógica. Jundiaí, SP: Paco Editorial, 2018.

POMBO, O. "Interdisciplinaridade e Integração dos Saberes". Lïnc em Revista, vol. 1, n. 1, 2005, pp. 3-15. 